\title{
La visión de Rusia y de España en la obra La eslavidad y el mundo del futuro de L'udovít Štúr (1815-1856)
}

\author{
RENÁTA BOJNIČANOVÁ
}

\begin{abstract}
The vision of Russia and Spain in Slavdom and the World of the Future of L'udovít Štúr. In his work Slovanstvo a svet budúcnosti (Slavdom and the World of the Future) Ludovít Štúr reflects on the past, present, and future of the peoples of Europe. As the Western world has, as he sees it, exhausted its role in history, it is the Eastern world that now plays a major part in the spiritual renewal of mankind. This basic idea colours Ludovít Štúr's view on Spain and Russia: while Spain represents the jaded, decadent Western world, Russia is an example of an ideal future society. This by far too negative consideration of Spain is in sharp contrast with a less than objective idealization of Russia.
\end{abstract}

Keywords: L'udovít Štúr, Slavdom, Spain, Russia

\section{Introducción}

El tema de este artículo es la imagen de Rusia y de España a mediados del siglo XIX contemplada desde un punto geográfico intermedio situado en el centro de Europa, concretamente desde Eslovaquia. Este planteamiento hace posible mostrar cómo se veían estas dos potencias políticas y culturales a distancia, desde fuera de sus fronteras, y desde el centro del continente del que forman dos extremos opuestos: el del Oriente y el del Occidente. $\mathrm{Me}$ intereso especialmente en la imagen que se tenía de estos dos pueblos europeos durante una época clave para la formación de las naciones modernas $y$, sin incurrir en generalidades, expondré las opiniones expresadas al respecto por la personalidad de la vida cultural eslovaca más capacitada para hacer esta reflexión, el líder del movimiento nacional eslovaco Ludovít Štúr (1815-1856), una de las figuras más insignes de la historia eslovaca.

La visión de Ludovít Štúr del pasado, del presente y del futuro de las naciones europeas, y no sólo europeas, está resumida en el controvertido ${ }^{1}$ escrito La eslavidad y el mundo del futuro (Das Slawentum und die Welt der

V. Matula considera esta obra como "la más problemática” de Ludovít Štúr, debido a "su contenido, sus conclusiones y la posibilidad de ser interpretada de muy diversas maneras" (Matula 1997: 130; traducción de RB). 
Zukunft, Славянство и мир будущего, Slovanstvo a svet budúcnosti) ${ }^{2}$, fruto de sus estudios teóricos sobre la historia, la filosofía, el arte, la cultura, etc. y de sus experiencias en la lucha política por los derechos del pueblo eslovaco.

La visión de Ludovít Štúr está condicionada por el idealismo romántico y por las teorías filosóficas vigentes en su tiempo, sobre todo las que se basaban en la creencia en el papel excepcional de los pueblos eslavos en la historia universal ${ }^{3}$. A pesar de estos puntos de vista tan predeterminados, es sorprendente su perspicacia en la mayoría de las observaciones acerca de la evolución de los pueblos de Europa. Algunas predicciones de Štúr son incluso tan acertadas que podrían considerarse proféticas. Por ejemplo, ya a mediados del siglo XIX Ludovít Štúr prevé la caída del Imperio Austro-Húngaro, que llegó a hacerse realidad en el año 1918. También advierte sobre la prepotencia del materialismo en las sociedades occidentales y sobre la pérdida de los valores espirituales y morales tradicionales basados en el cristianismo. Asimismo, con mucha vehemencia advierte sobre el peligro del comunismo naciente y predice que éste acabaría desembocando en el despotismo, el caos y la destrucción de los valores positivos, causando en los individuos el "aniquilamiento de toda su iniciativa, de la necesidad de autoafirmarse y del esfuerzo y el afán de competir con los demás" (Štúr 1993: 77; traducción de RB). La visión de Ludovít Štúr del futuro del Occidente es completamente negativa, definida con las palabras "decadencia", "destrucción", "declive", no sólo desde el punto de vista político, sino también moral y espiritual. Bien lo demuestra esta cita:

2 Ludovít Štúr escribió esta obra originalmente en alemán, pero el manuscrito quedó inédito. Se publicó por primera vez en año 1867 en una traducción al ruso (Славянство и мірь будущаго) llevada a cabo por el eslavófilo V. I. Lamanskij, quien la presentó en el Congreso Eslavo de Moscú. Fue editada por segunda vez también en Rusia en el año 1909 en San Petersburgo por iniciativa del eslavista ruso T. D. Florinskij. El manuscrito alemán fue publicado por primera vez en Eslovaquia en el año 1931, gracias al Dr. Josef Jirásek, profesor de la Universidad Comenius de Bratislava. La primera traducción al eslovaco fue realizada por Mikuláš Gacek en el año 1929, pero no pudo publicarse y quedó guardada en la Biblioteca Nacional Eslovaca. Finalmente esta obra llegó a las manos de los lectores eslovacos tan sólo en el año 1993, en la traducción hecha por Adam Bžoch a partir del original alemán.

3 En su visión de la historia y muy especialmente en su visión del papel histórico de los pueblos eslavos, Ludovít Štúr parte de las ideas filosóficas de G. W. F. Hegel y J. G. Herder y de la concepción cristiana de la historia de la humanidad como camino para la salvación. Como base de su pensamiento también toma en consideración los conceptos de la eslavidad de Ján Kollár (véase Dupkala 1997: 77-83). 
BOJNIČANOVÁ

Desde el punto de vista político, Occidente experimenta una transformación desde las monarquías absolutistas hacia los estados constitucionales, y éstos luego se convierten en repúblicas políticas, sociales y, por fin, comunistas, donde todo acaba en la descomposición de la humanidad y la destrucción del espíritu humanista. Esta evolución está marcada por la fatalidad: una vez que Occidente ha caído en el vértigo de estos procesos y no tiene fuerzas para salir de ellos. No hay alli ni sosiego, ni estabilidad, todo se precipita en avalancha $y$ todos ven su felicidad deseada y completa - ¡en la destrucción! Una revolución sucederá a otra y, tras cada una de ellas, las naciones occidentales quedarán en peor estado. Las generaciones venideras serán cada vez peores y más salvajes, porque ya ahora respiran este aire y se alimentan de su energía; este aliento occidental ha marcado también la educación y produjo un espíritu debilitado, somnoliento y desprovisto de cualquier exigencia; la molicie, el hedonismo y ostentación reemplazan cada vez más a la austeridad, la seriedad y la diligencia de tiempos pasados. (Štúr 1993: 113-114; traducción y pasajes resaltados en cursiva por RB.)

Como puede comprobarse, las reflexiones de L'udovít Štúr sobre la cultura occidental están caracterizadas por la desconfianza y la amargura. Para ello es necesaria una explicación acerca del momento en que fue escrita esta obra. Štúr la escribió a principios de los años 50 del siglo XIX, durante su estancia forzada en la pequeña ciudad de Modra, dónde estaba confinado bajo una estricta vigilancia policial tras la Revolución del 1848. Sin duda, sus opiniones estaban influidas por sus recientes experiencias en la lucha política, las cuales le llevaron a una gran decepción al sentirse traicionado por las autoridades vienesas, que no habían cumplido lo prometido a los eslovacos antes de la Revolución, a la vez que era consciente de la amenaza de los húngaros y sus pretensiones de magiarización de los eslavos. A todas estas decepciones nacionales se unía una profunda crisis individual, debida a la sensación de fracaso personal, acrecentada por el aislamiento y la presión policial. Poco después de escribir esta obra, Ludovít Štúr murió trágicamente, de modo que no pudo ocuparse de su divulgación. Como ya se constata en la nota no 2 , el manuscrito alemán fue traducido primero al ruso en dos ocasiones y en así fue dos veces publicado en Rusia, de modo que fue en lengua rusa como se conoció en el siglo XIX. Tan sólo en el siglo XX fue publicada la versión original alemana y posteriormente su traducción al eslovaco y, como se ha visto, no sin problemas. Las adversidades por las que tuvo que pasar esta obra indican que se trata de un escrito de contenido polémico y en cierto modo peligroso. Efectivamente, el peligro que esconde reside en el programa político que plantea, el cual consiste en dar la espalda al mundo occidental en decadencia y buscar la salvación de los eslavos de la Europa Central en el Oriente, cuyo representante era el Imperio Ruso. 
Es posible que si la obra de Štúr se hubiera podido difundir y propagar en su tiempo, y si, por el carisma de su autor, hubiera llegado a aplicarse en la práctica, posiblemente habría causado un cambio de rumbo en la historia de la Europa Central y Oriental. Esto, obviamente, no ocurrió, si bien tuvo por lo menos cierto influjo en la dirección de la vida cultural y política eslovaca. Los seguidores de Ludovít Štúr en la construcción nacional conocieron fragmentariamente esta obra y se atuvieron a sus consejos. Precisamente por la influencia de este legado de Štúr se suele explicar la marcada rusofilia de los intelectuales eslovacos desde la segunda mitad del siglo XIX hasta el fatídico año de 1968.

\section{Oriente y Occidente}

El pensamiento de Štúr tiene un amplio radio de intereses. Como patriota que era, en primer lugar dedicó sus fuerzas a buscar una solución para la pésima situación del pueblo eslovaco en el seno de la Monarquía Austro-Húngara, pero al mismo tiempo era consciente de que el problema de los eslovacos se podía resolver sólo de manera global, por medio de la promoción de un nuevo orden de fuerzas en el continente europeo. En su visión de la Europa del futuro, Štúr parte de una idea básica: Occidente ya está agotado y no puede aportar nada más a la Humanidad, por tanto, la salvación hay que buscarla de en el Oriente. Todo el pensamiento político de Štúr está basado en la oposición entre Occidente y Oriente, viendo estos dos polos como entidades opuestas en sus valores y en su papel histórico. De allí podemos partir en nuestra comparación de las dos visiones, la de España, como extremo occidental, y la de Rusia, como extremo oriental de Europa.

Por supuesto, las opiniones de Štúr estaban condicionadas, como más arriba se ha dicho, por la negativa experiencia provocada por el desinterés tanto de la corte vienesa como del parlamento húngaro hacia las reivindicaciones del pueblo eslovaco, planteadas en el documento titulado Peticiones del Pueblo Eslovaco (Žiadosti národa slovenského), publicado el 10 de mayo de 1848 en Liptovský Svätý Mikuláš. Por tanto, su reflexión está llena de amargura hacia el mundo germánico, al cual, aun admirando su ciencia y su capacidad intelectual, culpa de falta de sentimiento e incluso de brutalidad en el trato a las demás naciones. Los pueblos germánicos junto con los románicos son, según Ludovít Štúr, los que hasta entonces habían llevado el progreso de la humanidad, al considerarse herederos directos de la cultura clásica de griegos y romanos y, sin embargo, su fuerza vital parecía haberse ya agotado. Los pueblos germánicos han cumplido ya su papel en la historia, los alemanes al haber 
BOJNIČANOVÁ

transmitido a los pueblos europeos el cristianismo, y los austriacos al defender Europa contra los turcos. Por lo que se refiere a los pueblos románicos, Štúr tiene un mayor conocimiento de la historia y la cultura francesas, considerando como su punto culminante la campaña triunfal de Napoleón por Europa. Por lo demás, en los dos grupos de pueblos diagnostica los mismos problemas y prevé el mismo futuro: decadencia, crisis de valores, materialismo, inestabilidad política, extremismo social, empobrecimiento de las masas, etc. España es el país menos conocido por L'udovít Štúr, no obstante, también le dedica algunos comentarios.

\section{La visión de España}

La crítica que lanza Ludovít Štúr contra España en su Eslavidad y el mundo del futuro es inmisericorde, aunque sobre los españoles tiene sensiblemente mucha menos información y mucho menos conocimiento que acerca de los austriacos, alemanes, franceses e incluso ingleses. Con todo, en una página entera hace un resumen de la historia de España, en el cual plantea algunas observaciones muy acertadas, por ejemplo, constata muy sabiamente que la causa de la decadencia de España del siglo XVII se debe al mal aprovechamiento de las riquezas americanas. Sin embargo, lo que prevalece en las líneas dedicadas a España es la exposición de todos los tópicos de la leyenda negra atribuida a los españoles, los cuales aparecen a los ojos de Ludovít Štúr como un pueblo representante de la decadencia de la humanidad. Recuerda su crueldad hacia la población indígena de América, las represalias de duque de Alba en los Países Bajos, las prácticas sangrientas de la Inquisición, el dogmatismo religioso, y hace mención también del carácter impulsivo, poco diligente y fanático de los españoles. España, como país profundamente católico, no tocado por la Reforma, es en opinión L'udovít Štúr un buen ejemplo para estudiar “a dónde han llegado los países estrictamente católicos en educación, moral y laboriosidad” (Štúr 1993: 94). Por supuesto, no es un ejemplo a seguir. La culpa principal de todos los males del país la tiene la Inquisición y la riqueza mal administrada, por lo que la nación cayó en el letargo, la abulia y la inactividad, como se constata en el siguiente pasaje:

De este modo, la Inquisición y las riquezas obtenidas inmerecidamente han aniquilado toda clase de esfuerzo y actividad en el pueblo, el que después ha caído en una profunda apatía y letargo, estado en el que vemos permanecerle hasta hoy, habiendo perdido toda la fuerza para superarlo. (Štúr 1993: 95) (traducción y pasajes en cursiva resaltados por RB) 
Incluso los comentarios acerca de la Guerra de la Independencia, cuando España tomó conciencia de sí misma como nación moderna y vivió episodios de heroísmo, son muy poco favorables:

[Después de que Napoleón hubiera puesto en el trono a uno de sus hermanos...,] las masas exacerbadas por el fanatismo católico tomaron las armas, pero tuvieron que retroceder ante el disciplinado y combativo ejército francés [...]. Por segunda vez los extranjeros ayudaron a los españoles a librarse del dominio francés, y desde entonces [los españoles] varias veces han luchado entre sí a causa del mismo soberano por el cual antes se habían lanzado a combatir contra la invasión extranjera. La situación en la que se halla España ahora ya la hemos descrito más arriba; tanto el gobierno como el pueblo carecen de voluntad firme, todo lo contrario, por todas partes reina la falsedad, el letargo y la corrupción. (Štúr 1993: 95; traducción y pasajes en cursiva resaltados por RB.)

Es probable que estas ideas fueran copiadas y adaptadas por Ludovít Štúr a partir de algunas fuentes históricas alemanas, pues, de otra manera, poca información sobre España habría podido realmente tener. La crítica más feroz la lanza contra el catolicismo dogmático, que se había convertido, según él, en puro rito sin contenido. Indudablemente, Ludovít Štúr no tenía a su disposición toda la información sobre la grandiosa historia de los españoles en su Siglo de Oro, cuando sobre su Imperio "no se ponía el sol”, pero esto hay que entenderlo como resultado de la educación que había recibido, pues se formó en universidades alemanas y estuvo anclado culturalmente en el ambiente centroeuropeo, de modo que tenía un amplio conocimiento sobre el mundo eslavo y germánico, en tanto que su información sobre la historia y la cultura de España, alejada de sus intereses, dejaba mucho que desear. La prueba de que realmente no supo valorar el papel de España en la historia universal se ve en el hecho de que, por ejemplo, sí reconoce y valora la labor de los católicos en la difusión de la fe cristiana por el mundo, pero no hace mención alguna al mérito de los españoles en esta empresa, aunque, sin duda, lo han tenido más que otros pueblos. Tampoco valora la aportación indiscutible de los españoles al desarrollo de las artes y la expansión de la civilización occidental. En resumen, podemos constatar que la valoración que hace Štúr de la cultura española, que en sus ojos se reduce al mal ejemplo del catolicismo extremo y del huero dogmatismo, es intencionadamente negativa y llena de prejuicios, lo que puede tener raíz precisamente en las divergencias confesionales, ya que L'udovít Štúr era de confesión luterana.

De una manera absolutamente opuesta valora el extremo oriental de Europa, Rusia, a la cual atribuye unos méritos exageradamente engrandecidos. 
BOJNIČANOVÁ

\section{La visión de Rusia}

Para exponer su visión de Rusia, Ludovít Štúr también se sirve de tópicos, en este caso de mitos que difundían los eslavos en la creación de su autoimagen a lo largo del siglo XIX. Son tópicos generalmente conocidos y absolutamente indemostrables, como los de la laboriosidad de los pueblos eslavos, su hospitalidad, modestia, generosidad, su sentido de la igualdad y de la libertad, el apego a la familia y a la tierra, el espíritu pacífico, el respeto hacia cada ser humano, etc. Es interesante que Ludovít Štúr, en una obra tan seriamente planteada como ésta, eche mano de estas opiniones tan "folclóricas", lo que podemos atribuir a su idealismo y su parcialidad. Esto se debe también a que La eslavidad y el mundo del futuro tiene un objetivo básico, y es el de trazar el camino para la salvación de los pueblos eslavos que vivía en el seno de la Monarquía Austro-Húngara y estaban sometidos a una dura opresión después de la revolución del 1848. A partir de su reflexión se llega a una única solución, la de adherirse al asíllamado "hermano mayor", al pueblo ruso, el único pueblo eslavo que tenía en aquel entonces una entidad política independiente. En el fondo, la obra transmite una llamada a todos los pueblos eslavos para que aceptaran la supremacía del pueblo ruso y se decidieran a crear un estado común de los pueblos eslavos bajo la égida de Rusia. Así se explica el hecho de que Štúr cierra ojos ante los problemas reales de Rusia y transmite de ella una visión totalmente idealizada. Por ejemplo, afirma que los "míticos" e inherentes valores eslavos de la bondad y altruismo se hacen más patentes en los rusos que en otros pueblos de esa etnia, lo que ilustra con una serie de ejemplos que parecen más bien sacados de los cuentos de hadas: el zar habla como un padre con los campesinos más humildes (Štúr 1993: 122, 125); los soldados rusos reparten rublos de plata entre las mujeres húngaras (ib. 117); los oficiales rusos tratan a sus soldados como a amigos o hermanos y nunca se les oye decir palabrotas (ib. 127); un oficial ruso da limosna a un soldado húngaro inválido, en tanto que el oficial austriaco es capaz de hacerlo (ib. 115), etc. Además, idealiza también el sistema social, la situación económica y las prácticas de la política interior y exterior de Rusia. Por ejemplo, aunque se da cuenta de la existencia de la servidumbre, constata que ya está a punto de ser abolida y que, en el fondo, los campesinos rusos sufren menos que los campesinos en Hungría, porque su terrateniente, más que un despiadado señor feudal, es un padre bondadoso que vive con sus siervos "en una relación casi amistosa", ya que era costumbre que "en tiempos de penuria el terrateniente ayudara a sus siervos", compartiendo con ellos "las alegrías y también las penas" (ib. 119). Ludovít Štúr elogia la sociedad patriarcal rusa, convencido de que es el sistema que mejor conviene al espíritu de los pueblos eslavos. El elogio 
se dirige también a la religión ortodoxa que, según él, es la más verdadera y sincera, ya que el catolicismo está agotado y el protestantismo es demasiado racional. Para hacer esta propaganda política Štúr abusa de simplificaciones y tópicos: los rusos son el pueblo más respetuoso con sus enemigos, un pueblo de gran fe y sensibilidad social, capaz de dar ejemplo a los demás y liderarlos hacia un futuro próspero, etc.

L'udovít Štúr se ilusionaba con la idea de que los pueblos eslavos del centro de Europa y de los Balcanes se pudieran unir bajo la protección de este gran imperio patriarcal y formar juntos una unión inseparable. En su propuesta más extrema y sorprendente él, ¡el gran codificador de la lengua literaria eslovaca!, llega incluso a proponer que todos los pueblos utilizaran el ruso como lengua literaria. En la descripción elogiosa de la grandeza de Rusia hasta "roba" la expresión que se utilizaba para definir los dominios de Felipe II, "el Imperio donde nunca se pone el sol" (ib. 159). Sin embargo, no es esta grandeza exterior la principal razón que predestinaría a Rusia para liderar a los pueblos eslavos, sino las cualidades interiores del pueblo ruso, definido en términos completamente opuestos a lo que había escrito sobre los españoles:

La razón principal [de tomar el liderazgo de los pueblos eslavos] reside en la fuerza creadora del pueblo ruso y en su capacidad de sostener todo lo que ha creado. (Ib. 159; traducción y pasajes en cursiva resaltados por RB.)

Mientas que en Occidente, y muy en particular en España, Ludovít Štúr veía toda la decadencia que tiene raíces en el pasado y en el carácter inherente de los pueblos, en el Oriente, concretamente en Rusia, veía el motor del progreso de la Humanidad. En resumen, Rusia para él era el pueblo del futuro, un ideal para liderar a los pueblos eslavos y para cumplir la misión histórica de elevar a los seres humanos a las más altas cimas de la bondad.

\section{Conclusión}

Como se puede observar, Ludovít Štúr acertó en algunas de sus opiniones y predicciones sobre el futuro de los pueblos de Europa. Por ejemplo, se cumplió la predicción de que Rusia se pondría a la cabeza de los pueblos eslavos, tomando el papel del líder patriarcal, si nos referimos a la historia de Europa del siglo XX. También se cumplió la predicción sobre el cambio de los valores morales y espirituales en Occidente, aunque es discutible que sus consecuencias hayan sido tan catastróficas como las describe. Su visión apocalíptica se debe a que no lograba entender el sentido de los cambios que por aquel entonces ocurrían en 
BOJNIČANOVÁ

los países de Europa occidental, porque en el fondo era un hombre conservador. Él, que había sido líder del movimiento nacionalista eslovaco en el año 1848, renegó posteriormente de los ideales de la revolución y de la emancipación, y se aferró a los valores tradicionales. Aunque su concepción del mundo se basaba en observaciones ciertas y bien planteadas, no dejaba se estar fuertemente teñida de idealismo y de pasión. Su deseo de que las cosas fueran tal como él las sentía pesaba más que la realidad misma. De manera idealista creía en el futuro de los eslavos y en el papel que en su liderazgo debía cumplir el pueblo ruso. Esta convicción le llevó a una visión utópica de Rusia y, sobre todo, a una valoración muy poco objetiva de su sistema político y social. En cierto modo esta calidad "propagandística" de su escrito se puede explicar como un grito apasionado en pro de la salvación de los eslovacos, del mundo eslavo, y de la humanidad entera de todo aquello que preveía en sus catastróficas profecías de los tiempos venideros. La visión negativa de España, por otro lado, hay que atribuirla al poco conocimiento de la grandeza de la cultura española y también a los prejuicios que tenía contra España como país ultra-católico, cuya idiosincrasia no podía comprender desde su cultura y formación luterana.

De este modo, España y Rusia, como dos extremos de Europa desde el punto geográfico, están vistas por Ludovít Štúr como dos extremos opuestos en las perspectivas para el mundo del futuro.

\author{
Renáta Bojničanová \\ bojnicanova@fedu.uniba.sk \\ Comenius University in Bratislava, Faculty of Education (FEDU CU) \\ Univerzita Komenského v Bratislave \\ Pedagogická fakulta UK \\ Račianska 59 \\ Bratislava, 31334 \\ SLOVENSKO
}

\title{
Literatura
}

Dupkala, R. 1997. Štúrov hegelianizmus. - I. Sedlák, ed, L'udovít Štúr v súradniciach minulosti a súčasnosti. Martin: Matica slovenská, 77-83.

Harušiak, D. et al. 1994. Nad Tatrou sa blýska. Bratislava: SAV.

Hučko, J. 1988. Život a dielo L'udovíta Štúra. Martin: Osveta.

Juríček, J. 1976. L'udovít Štúr. Bratislava: Tatran.

Káša, P. 1997. Štúrova idea slovanstva medzi estetikou a politikou. - I. Sedlák, ed., L'udovít Štúr v súradniciach minulosti a súčasnosti. Martin: Matica slovenská, 146153. 
La visión de Rusia y de España en la obra La eslavidad

Krajčovič, M. 2010. Slovenské národné hnutie v medzinárodnom kontexte. Bratislava: SAP.

Matula, V. 1994a. Ludovít Štúr a slovanstvo. - D. Harušiak et al., eds., Nad Tatrou sa blýska, Bratislava: VEDA, 62-72.

Matula, V. 1994b. Štúrov spis Slovanstvo a svet budúcnosti. - I. Sedlák, ed., L'udovít Štúr v súradniciach minulosti a súčasnosti. Martin: Matica slovenská, 130-145.

Sedlák, I., ed. 1997. L'udovít Štúr v súradniciach minulosti a súčasnosti. Martin: Matica slovenská.

Štúr, L. 1967. Slavjanstvo i Mir" buduščago: poslanie Slavjanam" s" beregov" Dunaja. Perevod" neizdannoj německoj rukopisi, s" priměčanijami V. Lamanskago. Moskva: Izdanie Imperatorskago Obščestva Istrorii i Drevnostej rossijskich” pri Moskovskom" universitetě. = Штур А. 1967. Славянство и Мірб будущаго: посланіе Славянамъ съ береговъ Ауная. Переводъ неизданной нъмецкой рукописи, съ примъчаніями В. Маманскаго. Москва: ИзАаніе Императорскаго Общества Исторіи и Аревностей россійскнхъ при Московскомъ университеть.

Štúr L. 1993. Slovanstvo a svet budúcnosti [traducción al eslovaco de A. Bžoch]. Bratislava: Slovenský inštitút medzinárodných štúdií, ed. GORA.

Štúr L'. 2007. Dielo. Selección de textos, cometarios, notas, biografía y epílogo a cargo de $R$. Chmel. Bratislava: Kalligram. Ústav slovenskej literatúry SAV. 